\title{
Rietveld refinement, morphology and optical properties of $\left(\mathrm{Ba}_{1-x} \mathrm{Sr}_{x}\right) \mathrm{MoO}_{4}$ crystals
}

I.C. Nogueira ${ }^{\mathrm{a}}$, L.S. Cavalcante ${ }^{\mathrm{b}, \mathrm{c}^{*}}$, P.F.S. Pereira ${ }^{\mathrm{a}}$, M.M. de Jesus ${ }^{\mathrm{d}}$, J.M. Rivas Mercury ${ }^{\mathrm{d}}$, N.C. Batista ${ }^{\mathrm{c}}$, M. Siu Lid ${ }^{\text {d }}$ E. Longo ${ }^{\text {b }}$

${ }^{a}$ LIEC,UFSCar-DEMA, P.O. Box 676, 13565-905, São Carlos, SP, Brazil

${ }^{b}$ Instituto de Química-UNESP, P.O. Box 355, 14801-907, Araraquara, SP, Brazil

${ }^{c}$ UESPI, CCN, Departamento de Química, Rua João Cabral, P.O. Box 2231, 64002-150, Teresina-PI, Brazil

${ }^{d}$ Instituto Federal do Maranhão, Química, CEP 65025-001, São Luís, MA, Brazil

${ }^{e}$ IFSC, Universidade de São Paulo, P.O. Box 369, 13560-970, São Carlos, SP, Brazil

\section{Figures for the Supporting Information}

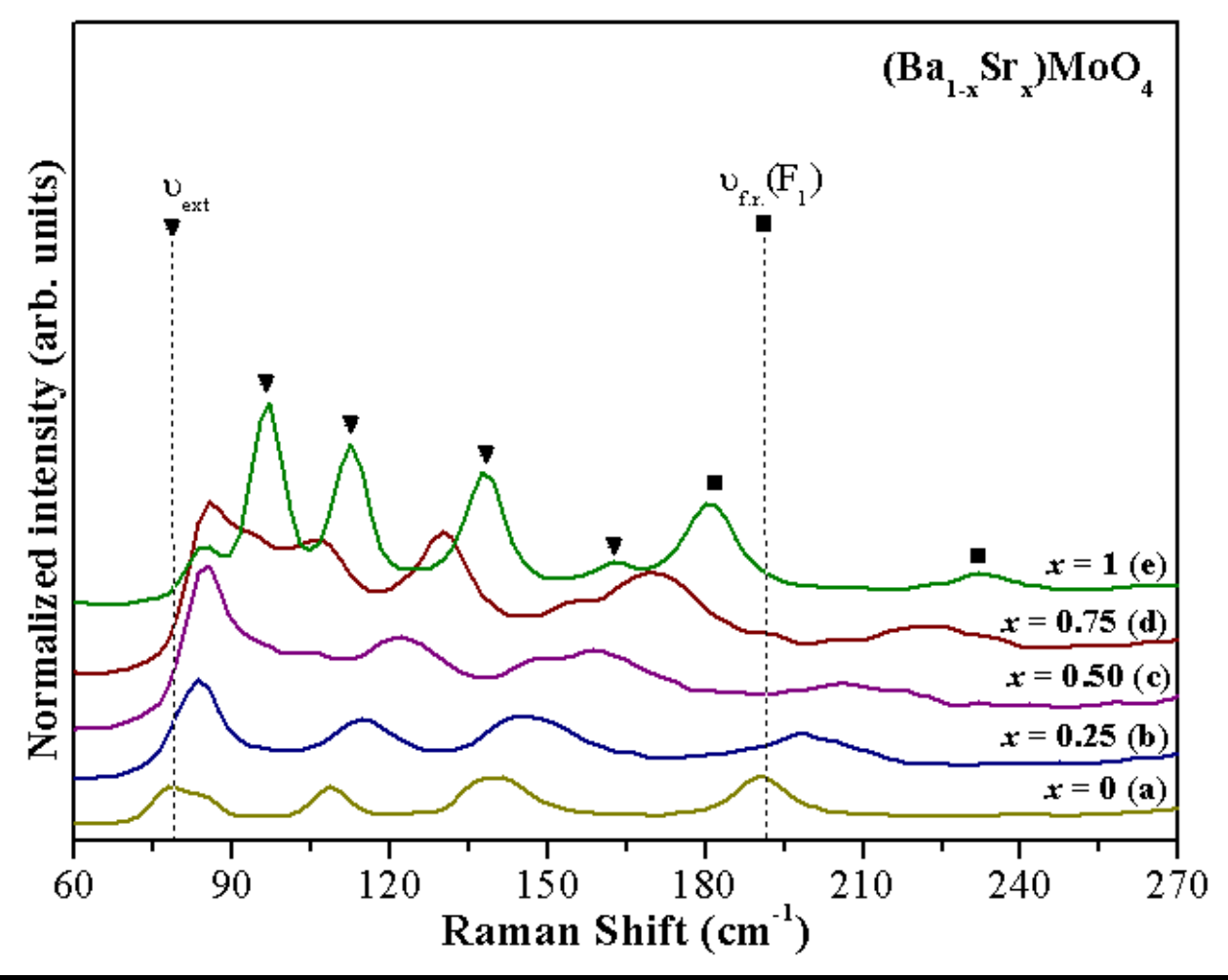

Figure SI-1: FT-Raman spectra in the range from 60 to $270 \mathrm{~cm}^{-1}$ of the $\left(\mathrm{Ba}_{1-x} \mathrm{Sr}_{x}\right) \mathrm{MoO}_{4}$ crystals with (a) $x=0$, (b) $x=0.25$, (c) $x=0.50$, (d) $x=0.75$ and (e) $x=1$ synthesized by the co-precipitation (drop by drop) method. 


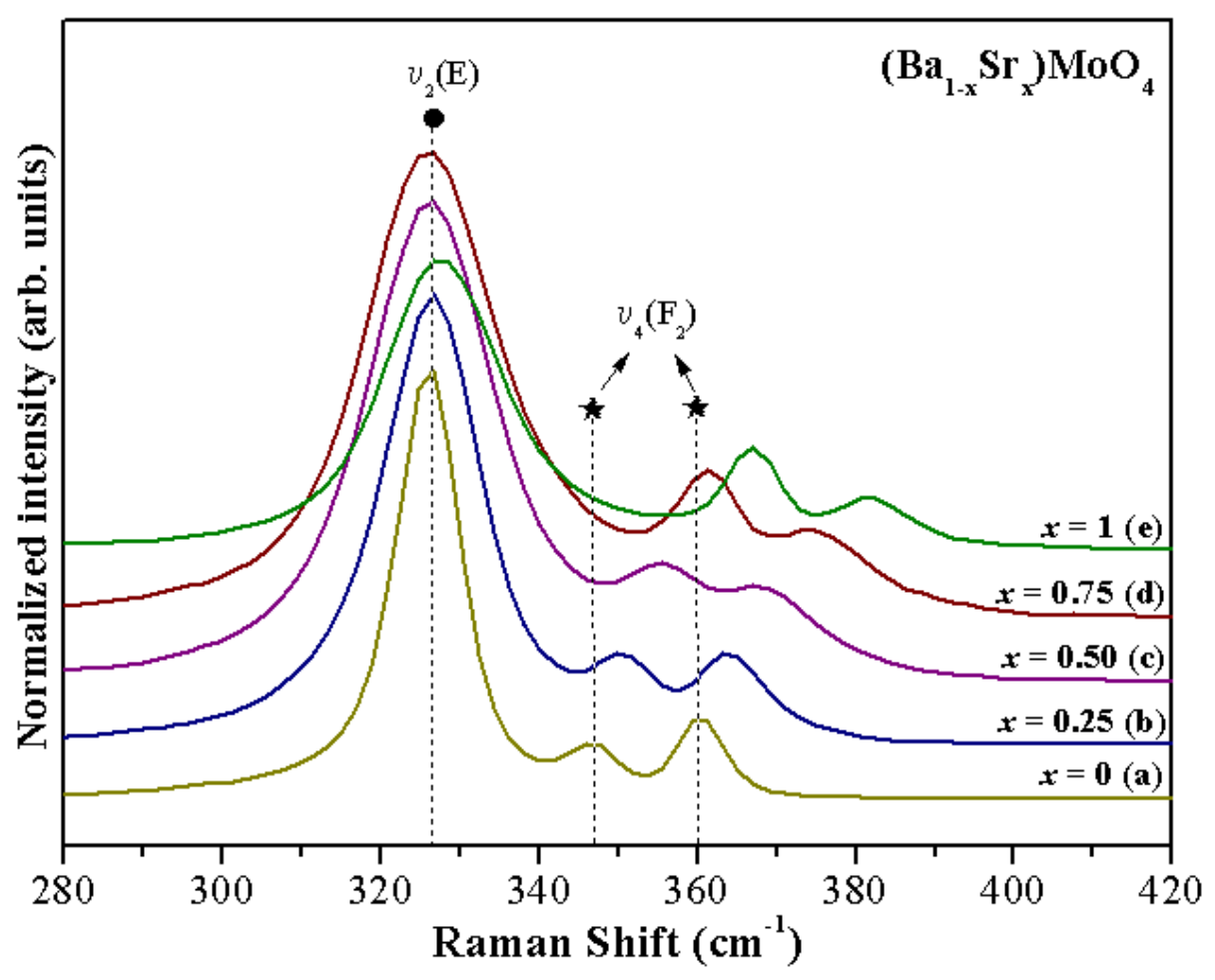

Figure SI-2: FT-Raman spectra in the range from 280 to $420 \mathrm{~cm}^{-1}$ of the $\left(\mathrm{Ba}_{1-x} \mathrm{Sr}_{x}\right) \mathrm{MoO}_{4}$ crystals with (a) $x=0$, (b) $x=0.25$, (c) $x=0.50$, (d) $x=0.75$ and (e) $x=1$ synthesized by the co-precipitation (drop by drop) method. 


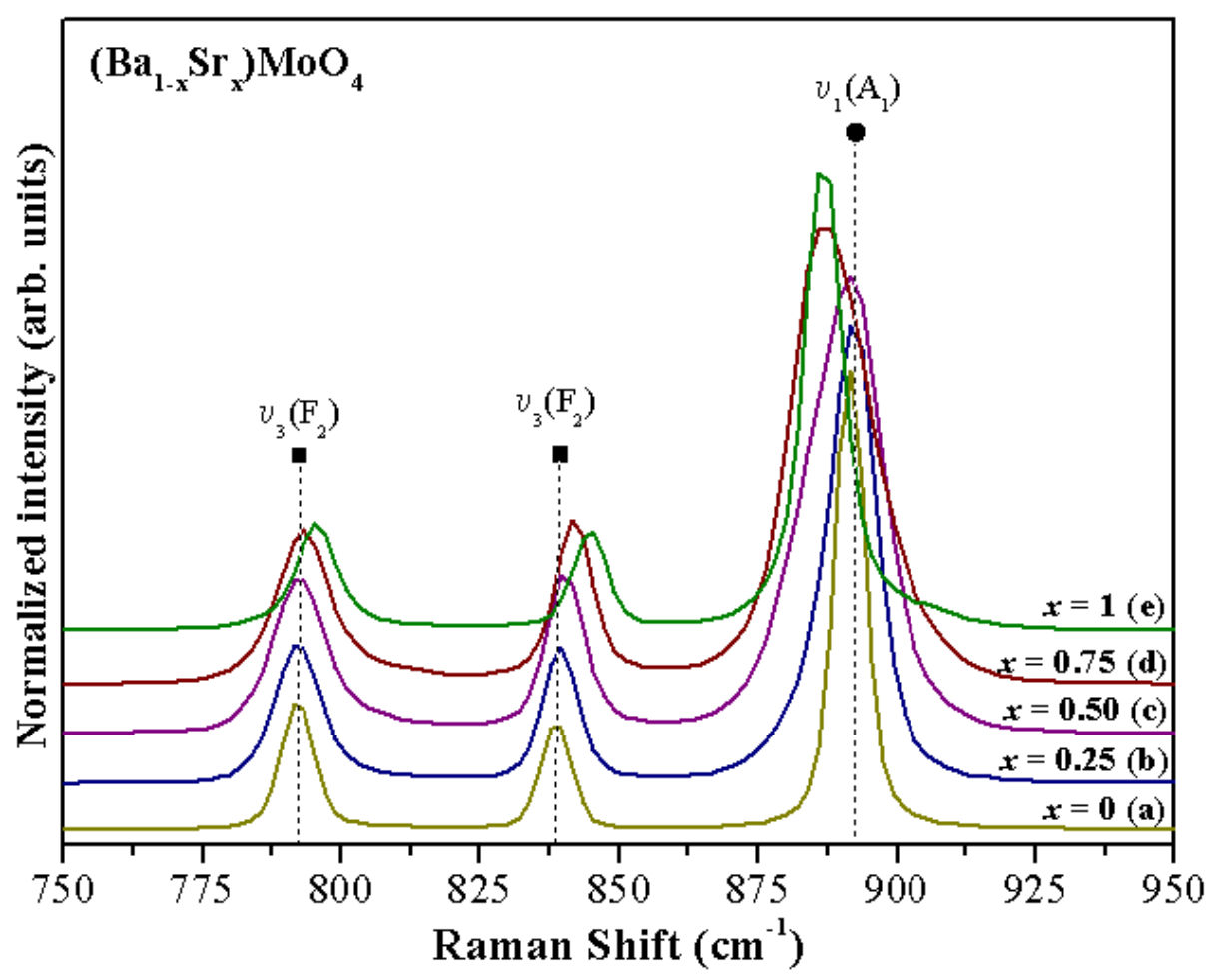

Figure SI-3: FT-Raman spectra in the range from 750 to $950 \mathrm{~cm}^{-1}$ of the $\left(\mathrm{Ba}_{1-x} \mathrm{Sr}_{x}\right) \mathrm{MoO}_{4}$ crystals with (a) $x=0$, (b) $x=0.25$, (c) $x=0.50$, (d) $x=0.75$ and (e) $x=1$ synthesized by the co-precipitation (drop by drop) method. 